\title{
Remote sensing of PM2.5 during cloudy and nighttime periods using ceilometer backscatter
}

\author{
Siwei $\mathrm{Li}^{1}$, Everette Joseph ${ }^{2}$, Qilong Min ${ }^{2}$, Bangsheng Yin ${ }^{2}$, Ricardo Sakai ${ }^{1}$, and Megan K. Payne ${ }^{1}$ \\ ${ }^{1}$ NOAA Center for Atmospheric Sciences, Howard University, Washington, DC 20001, USA \\ ${ }^{2}$ Atmospheric Sciences Research Center, State University of New York at Albany, Albany, NY 12203, USA \\ Correspondence to: Siwei Li (siwei.li@howard.edu)
}

Received: 17 September 2016 - Discussion started: 29 November 2016

Revised: 8 May 2017 - Accepted: 8 May 2017 - Published: 8 June 2017

\begin{abstract}
Monitoring PM2.5 (particulate matter with aerodynamic diameter $d \leq 2.5 \mu \mathrm{m}$ ) mass concentration has become of more importance recently because of the negative impacts of fine particles on human health. However, monitoring PM2.5 during cloudy and nighttime periods is difficult since nearly all the passive instruments used for aerosol remote sensing are not able to measure aerosol optical depth (AOD) under either cloudy or nighttime conditions. In this study, an empirical model based on the regression between PM2.5 and the near-surface backscatter measured by ceilometers was developed and tested using 6 years of data (2006 to 2011) from the Howard University Beltsville Campus (HUBC) site. The empirical model can explain $\sim 56$, $\sim 34$ and $\sim 42 \%$ of the variability in the hourly average PM2.5 during daytime clear, daytime cloudy and nighttime periods, respectively. Meteorological conditions and seasons were found to influence the relationship between PM2.5 mass concentration and the surface backscatter. Overall the model can explain $\sim 48 \%$ of the variability in the hourly average PM2.5 at the HUBC site when considering the seasonal variation. The model also was tested using 4 years of data (2012 to 2015) from the Atmospheric Radiation Measurement (ARM) Southern Great Plains (SGP) site, which was geographically and climatologically different from the HUBC site. The results show that the empirical model can explain $\sim 66$ and $\sim 82 \%$ of the variability in the daily average PM2.5 at the ARM SGP site and HUBC site, respectively. The findings of this study illustrate the strong need for ceilometer data in air quality monitoring under cloudy and nighttime conditions. Since ceilometers are used broadly over the world, they may provide an important supplemental
\end{abstract}

source of information of aerosols to determine surface PM2.5 concentrations.

\section{Introduction}

The adverse impacts of high PM2.5 (particulate matter with aerodynamic diameter $d \leq 2.5 \mu \mathrm{m}$ ) mass concentration on human health have been found from epidemiological studies around the world (Samet et al., 2000; Pope et al., 2009; Krewski et al., 2009). PM2.5 concentration has been found to be associated with cardiopulmonary disease, lung cancer, and an increased morbidity and mortality (Schwartz et al., 1996; Gent et al., 2003, 2009; Dominici et al., 2006; Bell et al., 2007; Franklin et al., 2007; Slama et al., 2007; Pope et al., 2002; Miller et al., 2007; Lepeule et al., 2012). As an official norm to stand for fine-particle abundance, PM2.5 mass concentrations are monitored widely by the US Environmental Protection Agency (EPA) through in situ instruments at surface monitoring sites. However, the number of EPA monitoring sites is limited. Therefore, remote sensing of PM2.5 from ground stations and satellites is desirable, allowing for fuller coverage of PM2.5 concentration between the EPA surface sites.

Aerosol optical depth (AOD) plays an important role in the remote sensing of PM2.5 since it has a good relationship with PM2.5 concentration. However, most measurements of AOD which are derived from passive remote-sensing techniques are only available under daytime and clear-sky conditions. Remote sensing of PM2.5 during either cloudy or nighttime periods is very rare. Different from passive instruments which measure column-integrated AOD, active 
instruments like advanced lidars have the capacity to provide the vertical distribution of aerosol backscatter coefficient even under cloudy conditions or at nighttime. However advanced lidar networks are rare due to the complexity and cost. Instead, ceilometers which are simple, automatically operating single-wavelength lidars are used broadly all over the world. Ceilometers were originally developed for cloud-based height retrieval. With the improvement of accuracy and power, the potential capabilities of ceilometers to detect mixing layer height and aerosol optical properties have been explored recently (Münkel et al., 2007; Markowicz et al., 2008; Heese et al., 2010; Tsaknakis et al., 2011; Wiegner and Geiß,2012). Another distinct advantage of ceilometers is their small overlap distance, which makes them suitable to detect aerosol information near the surface. PM2.5 concentration is an index of fine-particle mass concentration near the surface, while AOD is the integration of aerosol extinction in the total atmospheric column. So using aerosol backscatter near the surface has an inherent advantage in the remote sensing of PM2.5 concentration.

There are extensive studies investigating the PM2.5-AOD relationship by the use of either an empirical statistical method (Engel-Cox et al., 2004; Liu et al., 2005, 2009; Gupta et al., 2006; Koelemeijer et al., 2006; Gupta and Christopher, 2008; Paciorek et al., 2008; Di Nicolantonio et al., 2009; Schaap et al., 2009; Lee et al., 2012; Sorek-Hamer et al., 2013; Strawa et al., 2013; Chudnovsky et al., 2014; Hu et al., 2013, 2014; Ma et al., 2014) or a chemical transportation model (Liu et al., 2004; Van Donkelaar et al., 2006, 2010; Kessner et al., 2013; Xu et al., 2015). In these studies, aerosol vertical distributions are estimated based on model simulation or under an assumption that aerosols are well mixed within the boundary layer and then decrease exponentially with height. Recently Li et al. (2016) developed an algorithm combining the backscatter measured from ceilometers with AOD for the PM2.5 retrieval. That work showed the capability of the ceilometer to improve PM2.5 estimation by introducing measurements of aerosol optical properties near the surface. Although there are a plenty of studies on PM2.5 estimation, studies on the remote sensing of PM2.5 during either cloudy or nighttime periods are rare due to the limitation of measurements of AOD.

In this study, to estimate PM2.5 under cloudy or during night periods, we developed a regression model based on the relationship between PM2.5 and the ceilometer backscatter under different meteorological conditions. The model is tested and validated against the 6 years (2006-2011) of ground-based observations of ceilometer backscatter, PM2.5, AOD and meteorological conditions at the Howard University Beltsville Campus (HUBC) site and the 4 years (20122015) of data from the Atmospheric Radiation Measurement (ARM) Southern Great Plains (SGP) site. The data and model are described in Sect. 2. The results of the testing and evaluation of the model are illustrated in Sect. 3. The discussion is given in the last section.

\section{Data and model}

\subsection{Data}

In this study, the data were obtained from the HUBC site in Beltsville, MD, which is situated in a rural-suburban transition region between Washington, DC and Baltimore, MD urban centers. The site has a wide range of collocated instruments to observe atmospheric radiation, aerosol, cloud properties, meteorological conditions and air quality ( $\mathrm{Li}$ et al., 2016), which makes the HUBC site suitable for PM2.5 investigations.

The backscatter data were provided by a Vaisala CT25k ceilometer, which is a single-lens lidar system equipped with a pulsed near-infrared diode laser $(905 \mathrm{~nm})$. As a commercial ceilometer, the CT25k provides a range-corrected attenuated backscatter coefficient, but the raw data are not available to the customer, which limits the access of the correction process. However, it has been shown that the signal reduction due to the near-field problem can be compensated for well with the manufacturer's correction (Markowicz et al., 2008). The unique single-lens design gives full overlap of the transmitter and receiver field of view at an altitude of $0 \mathrm{~m}$ (Münkel et al., 2007), which allows CT25k ceilometers to obtain high signal-to-noise ratio for lidar return signals at a low altitude. The working wavelength of CT25k ceilometers is $\sim 905 \mathrm{~nm}$ where water vapor absorption exists (Wiegner et al., 2014; Wiegner and Gasteiger, 2015). However, water vapor impacts on backscatter retrieval are smaller than $\sim 2 \%$ for $905 \mathrm{~nm}$ ceilometers under midlatitude climatology (Wiegner and Gasteiger, 2015) within a short distance from the surface to the height of $150 \mathrm{~m}$. Given the small attenuation within a short distance, the attenuated backscatter coefficient below $150 \mathrm{~m}$ can be reasonably taken as a measure of backscatter coefficient when there is no rain or fog. The vertical resolution of the CT25k is $30 \mathrm{~m}$. Since we are interested in the PM2.5 concentration near the surface, we only use the first five layer backscatter measurements from the CT25k ceilometer to estimate PM2.5 concentrations. The choosing of $150 \mathrm{~m}$ is arbitrary, but the sensitivity test showed that the retrieval results are quite similar for the different heights from 90 to $300 \mathrm{~m}$ (Li et al., 2016). It worth noting that the CT25k is an uncalibrated instrument of which the response may change in time. That change may induce differences in retrieving attenuated backscatter at different times, especially in retrieving backscatter at high altitude where the signal-to-noise ratio is small (Kotthaus et al., 2016). To estimate the impacts of ceilometer response changing on backscatter measurements, we compared 3 years (2007, $2008,2009)$ of yearly average ceilometer backscatter profiles under nighttime clear conditions (PM2.5 $<15 \mu \mathrm{m}$, relative humidity $<40 \%$ ). The method is similar to the method used in Kotthaus et al. (2016) to illustrate impacts of background signal and cosmetic shift on ceilometer-reported signals. The largest difference of the yearly average backscatter 
below $150 \mathrm{~m}$ among the 3 years is found within $10 \%$ for the CT25k ceilometer.

The near-surface meteorological conditions - including temperature $(T)$, relative humidity $(\mathrm{RH})$, pressure, wind speed $(W)$ and wind direction - are provided by a nearby $31 \mathrm{~m}$ micrometeorological tower, and the AOD observations and cloud optical depth (COD) are retrieved from a Multifilter Rotating Shadowband Radiometer (MFRSR). The details of the MFRSR and the corresponding retrieval algorithms are introduced in Harrison et al. (1994), Harrison and Michalsky (1994) and Min and Harrison (1996). The hourly average PM2.5 are measured by a Met One BAM 1020 (beta ray attenuation monitor) from the collocated Maryland Department of the Environment (MDE) monitor station (Li et al., 2016).

In this study, hourly average data were used for all the data sets. Precipitation and fog cases were screened out by using cloud effective radius larger than $15 \mu \mathrm{m}$, microwave-radiometer-measured liquid water path larger than $200 \mathrm{~g} \mathrm{~m}^{-2}$, ceilometer-derived cloud layer lower than $200 \mathrm{~m}$ and relative humidity larger than $95 \%$.

\subsection{Model}

For a ceilometer, the energy observed is a function of backscattering coefficient

$P(x)=\frac{P_{0} A \eta O(x) C \Delta t}{2 x^{2}} \beta(x) T^{2}(x)$,

where $P(x)$ and $P_{0}$ are the received and emitted powers from a ceilometer; $A$ and $\eta$ are the area of the receiver and its efficiency, respectively; and $x$ is the range from receiver to scattering volume. $O(x)$ is overlap function, $C$ is light speed, $\Delta t$ is the laser pulse duration and $T(x)$ is the transmittance of the atmosphere between receiver and scattering volume. $\beta(x)$ is the backscattering coefficient, which can be separated into two components:

$\beta(x)=\beta^{\mathrm{m}}(x)+\beta^{\mathrm{a}}(x)$.

where $\beta^{\mathrm{m}}(x)$ and $\beta^{\mathrm{a}}(x)$ denote the backscattering by molecules and aerosols, respectively. The aerosol backscattering can be derived from the total backscattering coefficient as the molecule scattering is well modeled by Rayleigh scattering. For the backscattering at the near-infrared wavelength, the contribution from molecules can be disregarded due to the rapidly decreased Rayleigh scattering with wavelength, so $\beta(x)$ is taken as $\sim \beta^{\text {a }}(x)$ in this study.

With the assumption that aerosol size distribution is bimodal lognormal and aerosol particles are spherical, Li et al. (2016) illustrated that both the extinction and PM2.5 can be expressed in terms of particle volume concentration $\left(c v_{i}\right)$

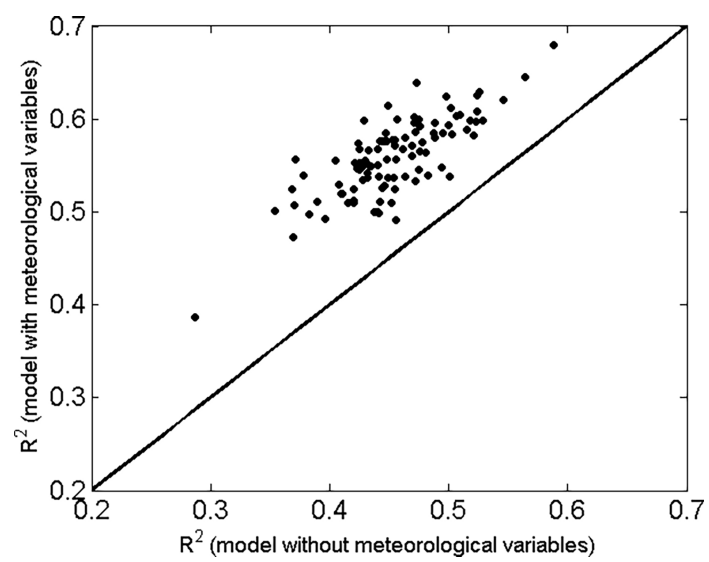

Figure 1. Comparison of $R^{2}$ out of the 100 independent crossvalidations for the model without meteorological variables (Eq. 11) and the model with meteorological variables (Eq. 12) based on all the available daytime clear-sky cases at the HUBC site.

Table 1. Parameters based on the best fitting of 100 independent tests for Eq. (9).

\begin{tabular}{lrrr}
\hline Best-fitting parameters & $a_{0}$ & $a_{1}$ & $b_{1}$ \\
\hline Daytime clear & -97.61 & 66.95 & 0.14 \\
Daytime cloudy & -100.00 & 94.02 & 0.05 \\
Nighttime & -100.00 & 85.70 & 0.08 \\
\hline
\end{tabular}

for each mode as

$$
\begin{aligned}
\operatorname{ext}(\lambda) & =\sum_{i=1}^{2} c v_{i} h\left(R_{i} \sigma_{i} m \lambda\right), \\
\operatorname{PM} 2.5 & =\sum_{i=1}^{2} c v_{i} g\left(R_{i} \sigma_{i} \rho\right),
\end{aligned}
$$

where $h\left(R_{i} \sigma_{i} m \lambda\right)$ and $g\left(R_{i} \sigma_{i} \rho\right)$ are the integral functions of volume-concentration-normalized aerosol size distribution; $c$ is the total particle volume concentration; $v_{i}$ is the fraction of volume concentration for each mode $i ; R_{i}$ and $\sigma_{i}$ are the geometric mean radius and the standard deviation of aerosol size distribution, respectively; $\lambda$ is the wavelength; $m$ is the refractive index; and $\rho$ is the particle mass density. The relationship between the aerosol backscattering coefficient $\beta^{\mathrm{a}}(\lambda)$ and the extinction coefficient $\operatorname{ext}(\lambda)$ at the wavelength $\lambda$ is usually expressed by a lidar ratio $(K)$ :

$K=\frac{\operatorname{ext}(\lambda)}{\beta^{\mathrm{a}}(\lambda)}$

From Eqs. (3), (4) and (5) the relationship between $\beta^{\mathrm{a}}(\lambda)$ and PM2.5 can be expressed by

$\mathrm{PM} 2.5=F \beta^{\mathrm{a}}(\lambda)$ 
Table 2. Parameters based on the best fitting of 100 independent tests for Eq. (10).

\begin{tabular}{lrrrrrrr}
\hline $\begin{array}{l}\text { Best fitting } \\
\text { parameters }\end{array}$ & $c_{0}$ & $c_{1}$ & $c_{2}$ & $c_{3}$ & $c_{4}$ & $d_{1}$ & $d_{2}$ \\
\hline Daytime clear & -10.50 & 3.49 & -2.92 & 0.06 & -0.11 & 0.07 & 0.55 \\
Daytime cloudy & -14.49 & 12.86 & -7.20 & 0.10 & -0.49 & 0.12 & 0.32 \\
Nighttime & -1.38 & 0.74 & -0.13 & 0.029 & -0.20 & 0.68 & 0.64 \\
\hline
\end{tabular}

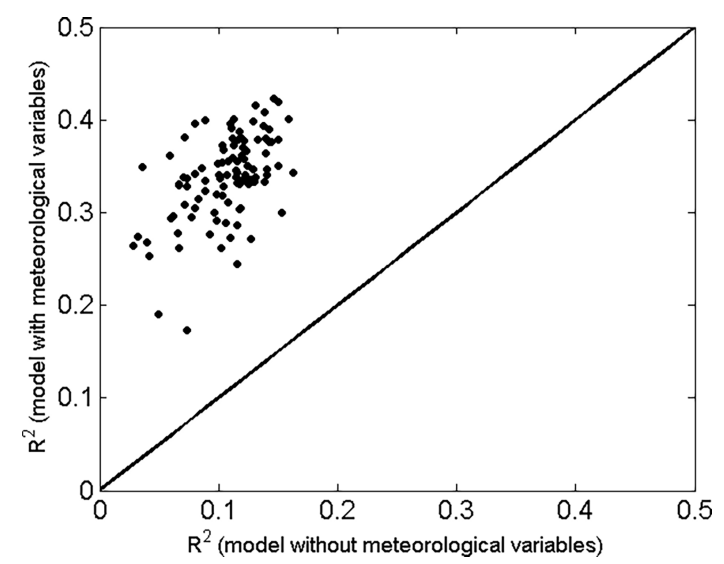

Figure 2. Same as Fig. 1 but just for cases under daytime cloudy conditions.

where

$$
F=K \frac{\sum_{i=1}^{2} v_{i} f\left(R_{i}, \sigma_{i}, m, \lambda\right)}{\sum_{i=1}^{2} v_{i} g\left(R_{i}, \sigma_{i}, \rho\right)},
$$

The PM2.5 / backscatter ratio $F$ only depends on aerosol size and composition. Given that the variation of aerosol size and composition could be associated with the meteorological conditions and the assumption that aerosols mixed well near the surface, an empirical model based on the relationship between PM2.5 and the backscatter near the surface is proposed as

$$
\begin{aligned}
\mathrm{PM}_{2.5} & =a_{0}+\left(a_{1}+a_{2} f(\mathrm{RH})+\sum_{i=1}^{n} a_{2+i} M_{i}\right) \\
& \left(\int_{0}^{z} \beta(x, \lambda) \mathrm{d} x\right)^{b_{2}}+\varepsilon,
\end{aligned}
$$

where the hygroscopic grow factor is expressed as

$f(\mathrm{RH})=\frac{1}{(1-\mathrm{RH})^{b_{1}}}$.

RH is relative humidity; $M_{1}$ through $M_{n}$ are the meteorological factors including surface temperature, wind speed, wind direction and surface pressure; $z$ is height; $a_{0}$ through $a_{2+n}$,

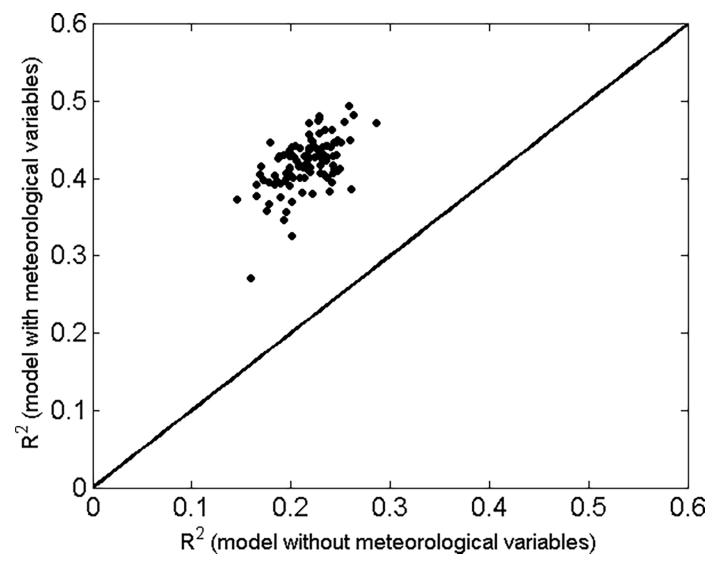

Figure 3. Same as Fig. 1 but just for cases during nighttime periods.

$b_{1}$ and $b_{2}$ are the regression coefficients; and $\varepsilon$ is the error term. In the following part, we will test the model performance without considering the meteorological variables. In that case, Eq. (8) can be expressed as

$\mathrm{PM}_{2.5}=a_{0}+a_{1}\left(\int_{0}^{z} \beta(x, \lambda) \mathrm{d} x\right)^{b_{1}}+\varepsilon$.

When we test the model including the impacts from observations of surface $T, \mathrm{RH}$ and $W$, Eq. (8) can be expressed as

$$
\begin{aligned}
\mathrm{PM}_{2.5} & =c_{0}+\left(c_{1}+c_{2} \times \frac{1}{(1-\mathrm{RH})^{d_{1}}}+c_{3} T+c_{4} \times W\right) \\
& \left(\int_{0}^{z} \beta(x, \lambda) \mathrm{d} x\right)^{d_{2}}+\varepsilon .
\end{aligned}
$$

\section{Results}

Overfitting can occur when a regression model is too complex. The overfitted model describes random error or noise instead of the underlying relationship. To test and evaluate the model, cross-validations (CVs) are implemented on the 6 years of hourly average measurements at the HUBC site under the different conditions including daytime clear, daytime cloudy and nighttime periods. For the cross-validation, we randomly select $90 \%$ of the data as a training data set, use the remaining $10 \%$ to test the models and repeat the procedure 100 times to avoid random bias and misleading $R^{2}$ induced by overfitting. Cross-validations are conducted for each model under each condition.

\subsection{Simulation results under different sky conditions}

Under daytime clear-sky conditions when AOD measurements from the MFRSR are available (no cloud, daytime), 

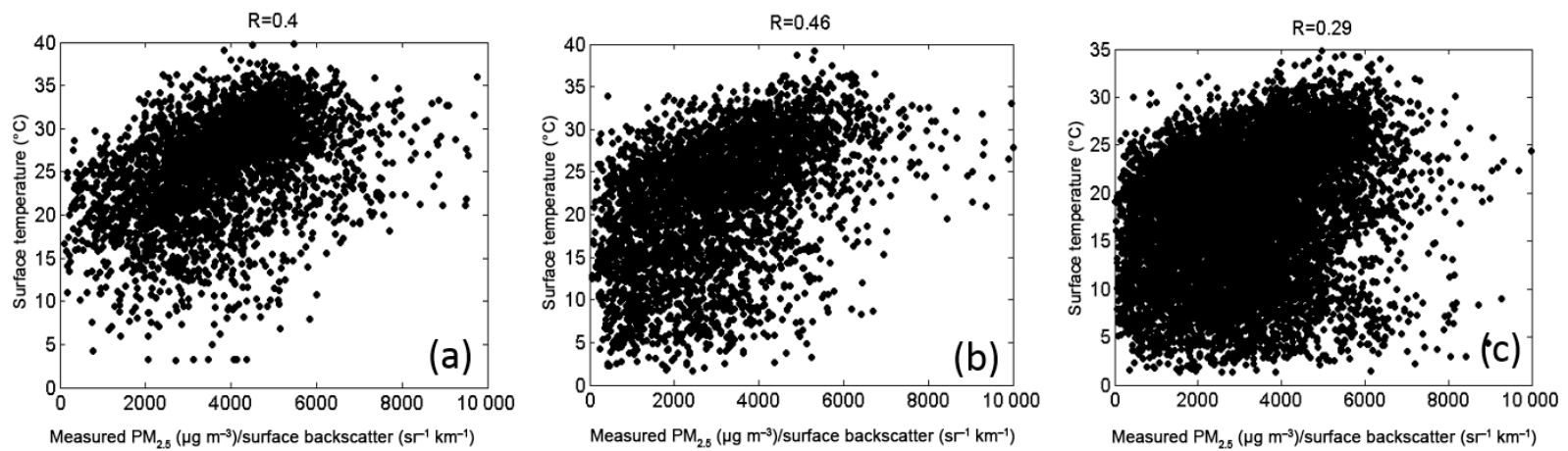

Figure 4. The relationship between surface temperature and PM2.5/backscatter ratio for (a) daytime clear-sky cases, (b) daytime cloudy cases and (c) nighttime cases.
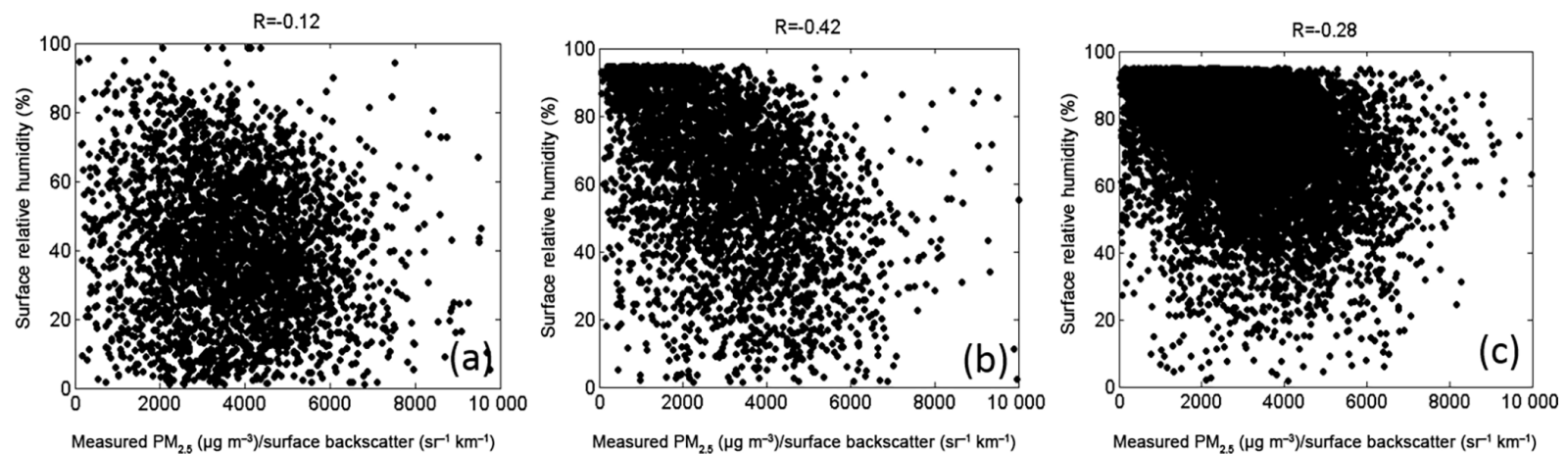

Figure 5. The relationship between surface relative humidity and PM2.5/backscatter ratio for (a) daytime clear-sky cases, (b) daytime cloudy cases and (c) nighttime cases.

the average $\mathrm{CV} R^{2}$ out of the 100 times random crossvalidations for the model (Eq. 10) is 0.56 (Fig. 1) with a root mean square error (RMSE) of $6.12 \mu \mathrm{g} \mathrm{m}^{-3}$. This result is close to that of the nonlinear model which combines both AOD and the ceilometer backscattering $\left(\mathrm{CVR}^{2}=0.60\right.$, $\mathrm{RMSE}=5.83 \mu \mathrm{g} \mathrm{m}^{-3}$ ) developed by Li et al. (2016) and performed much better than that of the model using AOD only $\left(\mathrm{CVR}^{2}=0.40, \mathrm{RMSE}=7.14 \mu \mathrm{g} \mathrm{m}^{-3}\right.$; Li et al., 2016). Without considering the meteorological conditions (Eq. 9), the average $\mathrm{CVR}^{2}$ of the model is 0.45 (Fig. 2), which is better than that of the model using AOD only (Li et al., 2016) but not as good as the model including meteorological variables. Based on the fitted parameters (the parameters of the best fitting are shown in Tables 1,2) from the 100 independent cross-validations ( $10 \%$ of the total data), the average correlation coefficient between all the in situ measured PM2.5 under daytime clear-sky conditions and the simulated PM2.5 from the model without meteorological variables is 0.68 and increased to 0.76 when meteorological variables were included (Eq. 10).

Remote sensing of AOD is commonly based on the measurements of spectral extinction of solar radiation due to aerosol scattering and absorption in the atmospheric column from passive instruments. However most passive instruments cannot readily discern AOD from COD under cloudy conditions. So any PM2.5 remote-sensing method relying on passive AOD measurements cannot retrieve PM2.5 under cloudy conditions. However, measurements of backscatter under cloudy conditions are still available for ceilometers, which can help to determine the near-surface aerosol extinction when upper-layer clouds exist.

Under daytime cloudy conditions, the average $\mathrm{CVR}^{2}$ of the model without meteorological variables is only 0.11 (Fig. 2), which means only around $11 \%$ of the variability in the hourly PM2.5 can be explained by the model. When meteorological factors are considered, the model can explain $34 \%$ of the variability. Based on the fitted parameters of the 100 independent cross-validations, the average correlation coefficient between all the in situ measured PM2.5 under daytime cloudy conditions and the simulated PM2.5 from the model without meteorological variables is only 0.34 , and it improved to 0.59 when meteorological variables were included in the model.

During nighttime periods, passive measurement relying on solar radiation is not available, but active instruments like ceilometers are still able to measure regardless of solar radiation and have better signal-to-noise ratio because of the absence of background sunlight contamination. During night- 

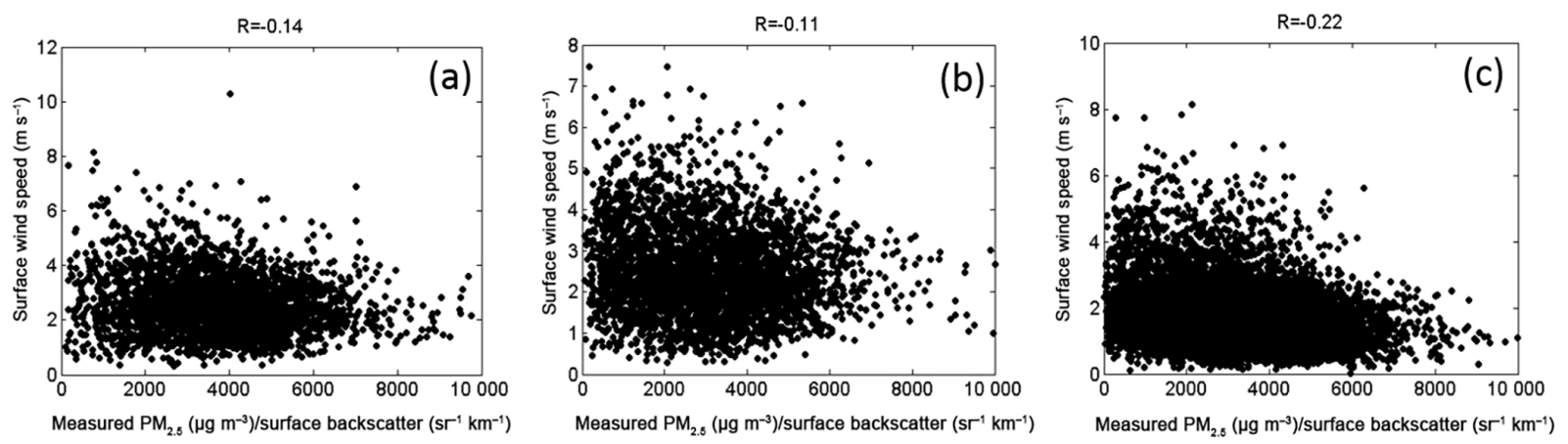

Figure 6. The relationship between surface wind speed and PM2.5/backscatter ratio for (a) daytime clear-sky cases, (b) daytime cloudy cases and (c) nighttime cases.
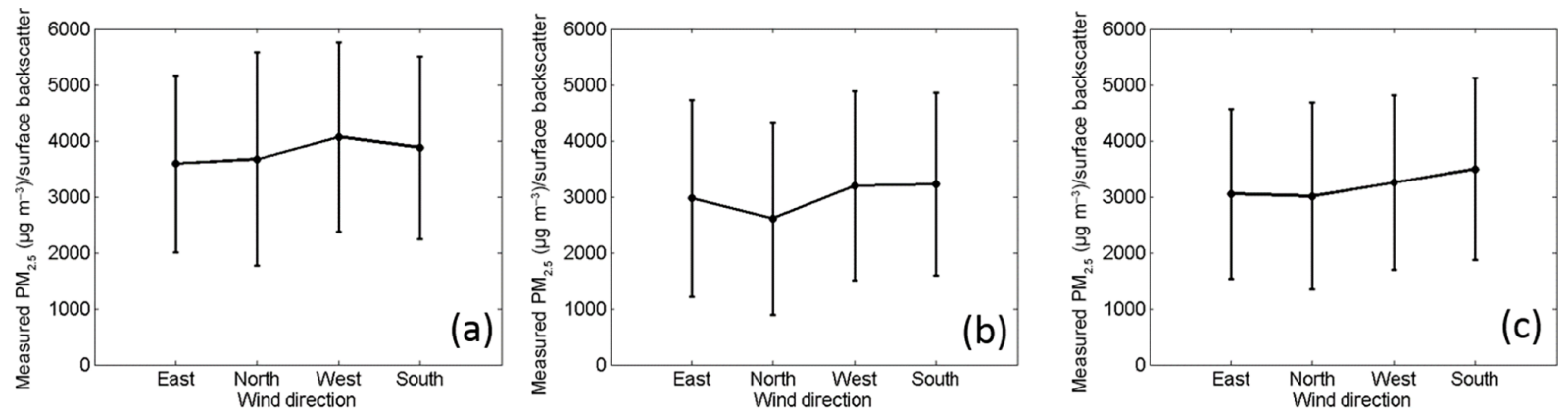

Figure 7. Average PM2.5/backscatter ratio with standard deviation at four direction ranges - east $\left(315\right.$ to $\left.45^{\circ}\right)$, north $\left(45\right.$ to $\left.135^{\circ}\right)$, west $\left(135\right.$ to $\left.225^{\circ}\right)$ and south $\left(225\right.$ to $\left.315^{\circ}\right)$ - for (a) daytime clear cases, (b) daytime cloudy cases and (c) nighttime cases.

time periods, the average $\mathrm{CVR}^{2}$ out of the 100 independent cross-validations for the model without meteorological variables is 0.21 , while the average $\mathrm{CVR}^{2}$ for the model with meteorological variables is 0.42 (Fig. 3). In this study, measurements under clear sky and cloudy sky were not separated during nighttime periods. Based on the fitted parameters of the 100 independent tests, the average correlation coefficient between all the in situ measured PM2.5 during nighttime and the simulated PM2.5 from the model without and with meteorological variables was 0.47 and 0.65 , respectively.

\subsection{Impacts from meteorological variables}

The previous results showed that without considering meteorological factors the model predicting ability largely decreased, especially under cloudy and nighttime conditions. Remote sensing of PM2.5 using backscattering coefficients is based on the relationship between PM2.5 and aerosol backscatter which is determined by aerosol physical and chemical properties. Aerosol physical and chemical characteristics are sensitive and dependent on meteorological conditions that can impact aerosol transportation, hygroscopic growth and aerosol nucleation/creation. Therefore, meteorological conditions can be potentially used to estimate aerosol characteristics when the direct observations are not available. So taking into account the variations of meteorological con- ditions may largely improve the model which is based on the regression between PM2.5 and backscattering coefficients.

To investigate impacts from different meteorological factors on PM2.5 remote sensing, the relationship between each meteorological variable and the PM2.5/backscatter ratio were analyzed in three data categories: daytime clear (AOD measurements are available), daytime cloudy and nighttime (Figs. 4-7). Among the meteorological variables, temperature was found to have the most prominent positive correlation with the PM2.5/backscatter ratio. The correlation coefficients are equal to $0.4,0.46$ and 0.29 under daytime clear, daytime cloudy and nighttime conditions, respectively (Fig. 4). In the eastern United States, sulfate dominates the aerosol chemical composition (Hand et al., 2012), and sulfate concentrations are expected to increase with increasing temperature due to faster $\mathrm{SO}_{2}$ oxidation. Fine particles have smaller backscatter coefficients due to the smaller size index based on Mie theory (Wiscombe, 1980) than larger particles with the same PM2.5 mass concentration. So at the HUBC site, the increase of temperature associated with the high PM2.5 / backscatter ratio could be due to the increase of fine particles.

As opposed to the surface temperature, it is shown that the surface relative humidity had a prominent negative association with the PM2.5/backscatter ratio. The correlation coefficient is equal to $-0.12,-0.42$ and -0.28 under the 

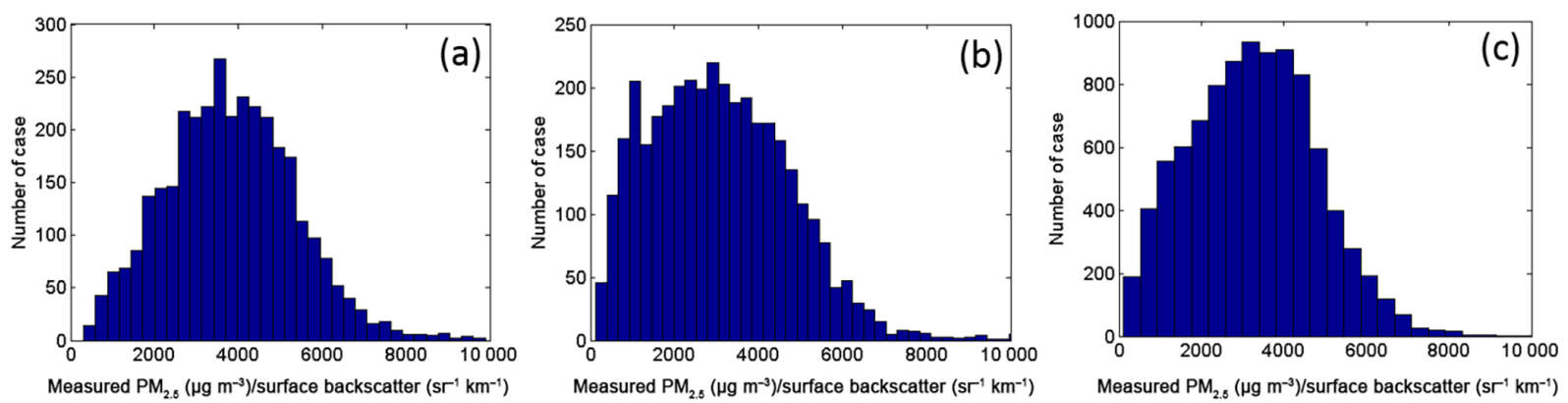

Figure 8. The number distribution of PM2.5 / backscatter ratio for (a) daytime clear cases, (b) daytime cloudy cases and (c) nighttime cases.

Table 3. Cross-validation tests of the model with different meteorological variables included.

\begin{tabular}{lrr}
\hline Test & $\begin{array}{r}R^{2} \\
\text { (RMSE) }\end{array}$ & $\begin{array}{r}\text { 95\% confidence intervals } \\
\text { of } R^{2} \text { (of RMSE) }\end{array}$ \\
\hline Test1: model including all available meteorological variables & $0.43(6.70)$ & $0.421-0.429(6.672-6.736)$ \\
Test2: model without surface temperature & $0.37(7.01)$ & $0.367-0.375(6.981-7.044)$ \\
Test3: model without relative humidity & $0.39(6.91)$ & $0.385-0.393(6.880-6.946)$ \\
Test4: model without wind speed & $0.37(7.01)$ & $0.368-0.375(6.978-7.043)$ \\
Test5: model without wind direction & $0.42(6.71)$ & $0.420-0.428(6.683-6.742)$ \\
Test6: model without surface pressure & $0.42(6.71)$ & $0.421-0.429(6.674-6.738)$ \\
Test7: model not including any meteorological variable & $0.21(7.88)$ & $0.203-0.209(7.846-7.914)$ \\
\hline
\end{tabular}

daytime clear, daytime cloudy and nighttime conditions, respectively (Fig. 5). Under high-relative-humidity conditions there can be significant variations in the aerosol optical properties due to the aerosol hygroscopic growth effect. In the eastern United States, the dominant aerosols are composed of ammonium sulfate aerosols for which the ambient size will increase with the increase of the relative humidity due to hygroscopic growth. That can result in the decrease of the PM2.5 / backscatter ratio due to the increase of the aerosol extinction cross section while the aerosol dry mass is relatively invariant. It should be noted that the correlation coefficient is -0.12 for the cases under daytime clear conditions, while it is -0.42 under daytime cloudy conditions. Chu et al. (2015) showed that the effect of hygroscopic growth on extinction is more prominent when the relative humidity is larger. Under nighttime conditions, including both the clear and cloudy situations, the correlation coefficient is -0.28 .

A negative association is also found between the wind speed and PM2.5/backscatter ratio under all the three conditions (Fig. 6). That may be explained by the association of higher PM2.5 concentrations with more stagnant, weaker wind conditions (Tai et al., 2010). Based on the average PM2.5/ backscatter ratio at four wind direction ranges - east $\left(315\right.$ to $\left.45^{\circ}\right)$, north $\left(45\right.$ to $\left.135^{\circ}\right)$, west (135 to $\left.225^{\circ}\right)$ and south $\left(225\right.$ to $\left.315^{\circ}\right)$ - the variation of the mean PM2.5 / backscatter ratio at the four different wind directions was found to be small (within 10\%) compared to the standard deviation $(\sim 50 \%$ of the mean value) at the HUBC site
(Fig. 7). The association of the surface pressure with the PM2.5 / backscatter ratio was found to be weak, with the correlation coefficient equal to -0.05 (not shown). The distributions of PM2.5/backscatter ratio under the three conditions are shown in Fig. 8. Statistically, the PM2.5/ backscatter ratio under daytime clear-sky conditions is larger than that under daytime cloudy or nighttime conditions.

Figures 4-7 show the potential impacts of meteorological factors on model prediction. However, some information possibly overlaps among the different meteorological variables. To investigate the contribution of each meteorological variable to improving the model predicting power, the model was tested with different meteorological variable combinations. For each test, the cross-validation was randomly repeated 100 times based on all the available cases, including the daytime clear, daytime cloudy and nighttime periods.

Table 3 demonstrates the average $\mathrm{CVR}^{2}$, RMSE and $95 \%$ confidence intervals for each test. It is shown that without the information of surface temperature, relative humidity or wind speed the average $\mathrm{CVR}^{2}$ of the model decreases from 0.43 to $0.37,0.39$ or 0.37 , respectively. In other words, adding the variable of surface temperature, relative humidity or wind speed into the model can bring in additional information which may improve the model prediction capability regarding PM2.5. 

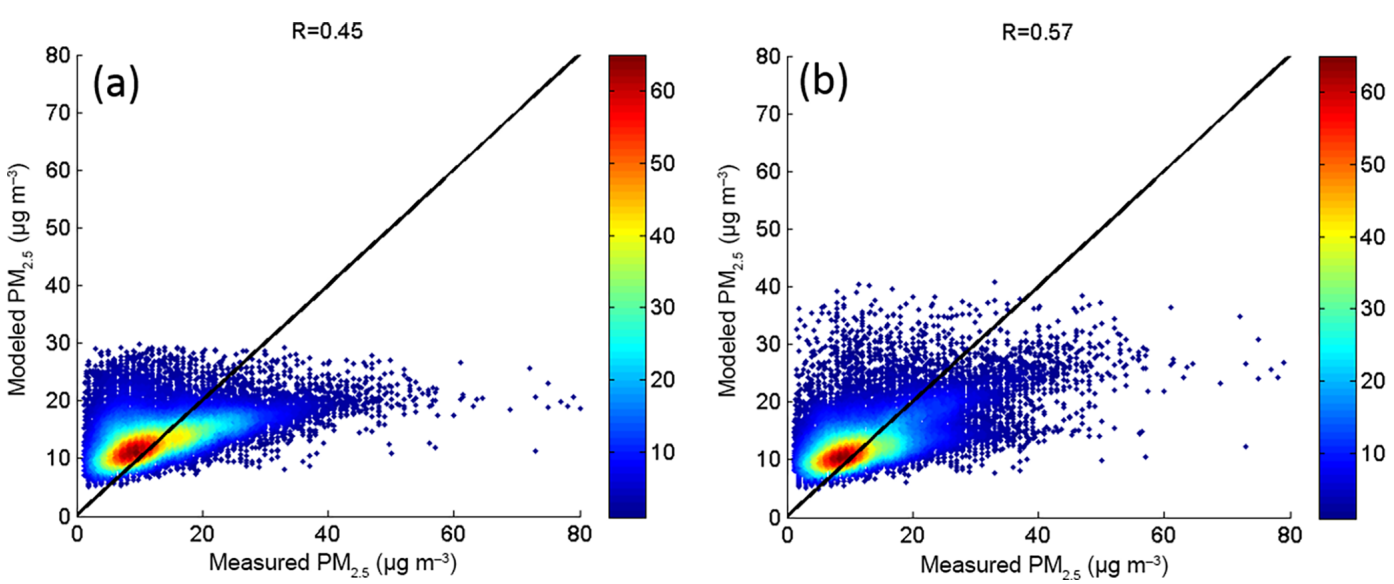

Figure 9. Comparison of measured PM2.5 and modeled PM2.5 when meteorological variables are not taken into account. (a) The model is non-seasonally fitted, and (b) the model is seasonally fitted. The colors stand for the number density of the points.
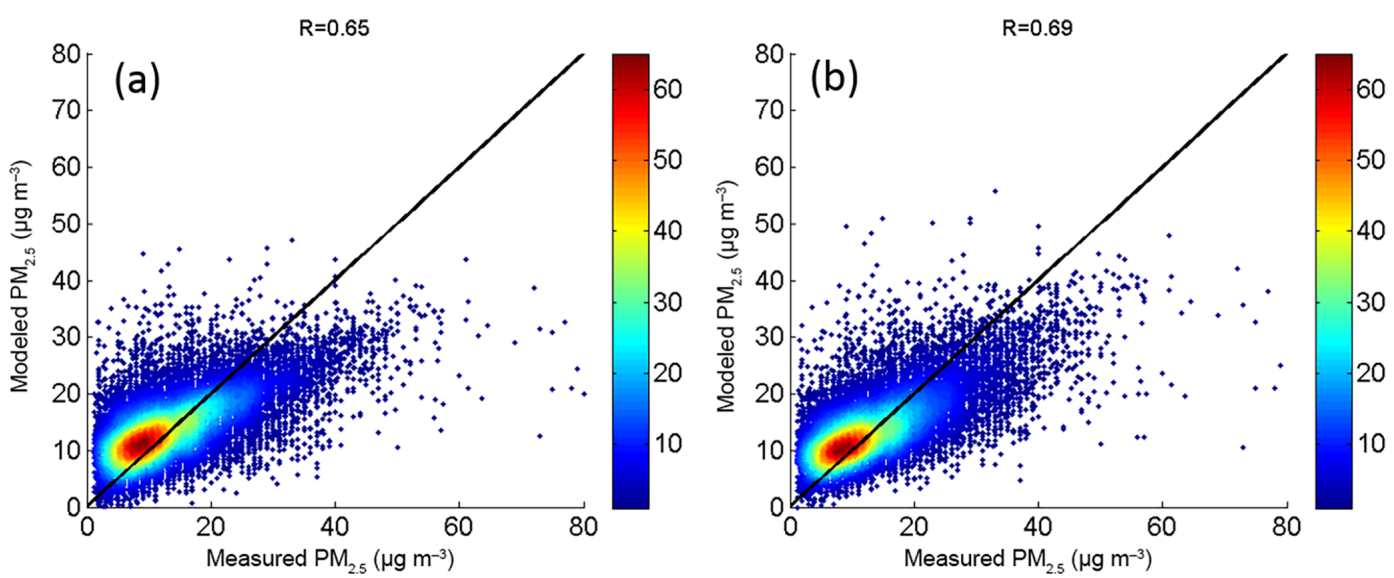

Figure 10. Same as Fig. 9 but with all meteorological variables taken into account.

\subsection{Seasonally fitting}

Besides meteorological factors, the seasonal variations of aerosol physical and chemical properties could impact the PM2.5 / backscatter ratio and then PM2.5 retrievals. To investigate the impacts of seasonal variations on PM2.5 retrievals, we fit the model seasonally and compared that performance with the model fitted on all the data without considering seasonal variation. Just as in the previous section, the cross-validations were implemented for each test. The parameters of the fitting with the median $\mathrm{CVR}^{2}$ out of the 100 independent cross-validations for each fitting method are used to calculate the correlation between the in situ measurements of PM25 and the simulated PM2.5. When meteorological variables were not considered, the simulated PM2.5 from the model with the seasonally fitted parameters had a much stronger association with the in situ measured PM2.5 ( $R=0.57)$ than the model with the non-seasonally fitted parameters $(R=0.45$; Fig. 9). When meteorological variables were taken into account, the correlation coefficient between the simulation and the in situ measurements of PM2.5 for the model with the seasonally fitted parameters and the model with the non-seasonally fitted parameters was 0.69 and 0.65 , respectively (Fig. 10), and the average $\mathrm{CVR}^{2}$ was 0.48 and 0.43 . The meteorological conditions have seasonal variation, so taking into account meteorological variables in the model can mitigate downside impacts of ignoring seasonal variations of aerosol properties on PM2.5 prediction.

\subsection{Test in a different region}

Given that aerosol types, aerosol compositions and meteorological conditions could be different in a different region, the model was tested based on the observations at the ARM SGP site, which is located in Oklahoma, USA. The site is in a rural area with fewer anthropogenic aerosols than the HUBC and the DC area. The ARM SGP site is the largest and most extensive climate research field site in the world. A newer version of the Vaisala Ceilometer CL31 has been used instead of the Vaisala CT25K since 2010 at the ARM SGP site. 

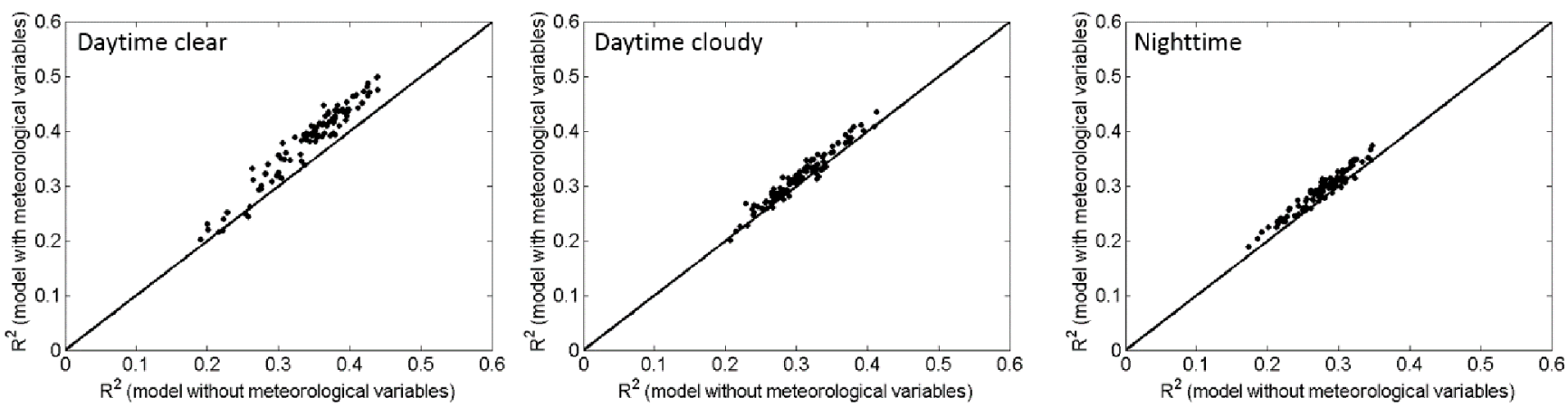

Figure 11. Comparison of cross-validation $R^{2}$ of the model without meteorological variables and model with meteorological variables during daytime clear, daytime cloudy and nighttime periods with the data from ARM SGP site.
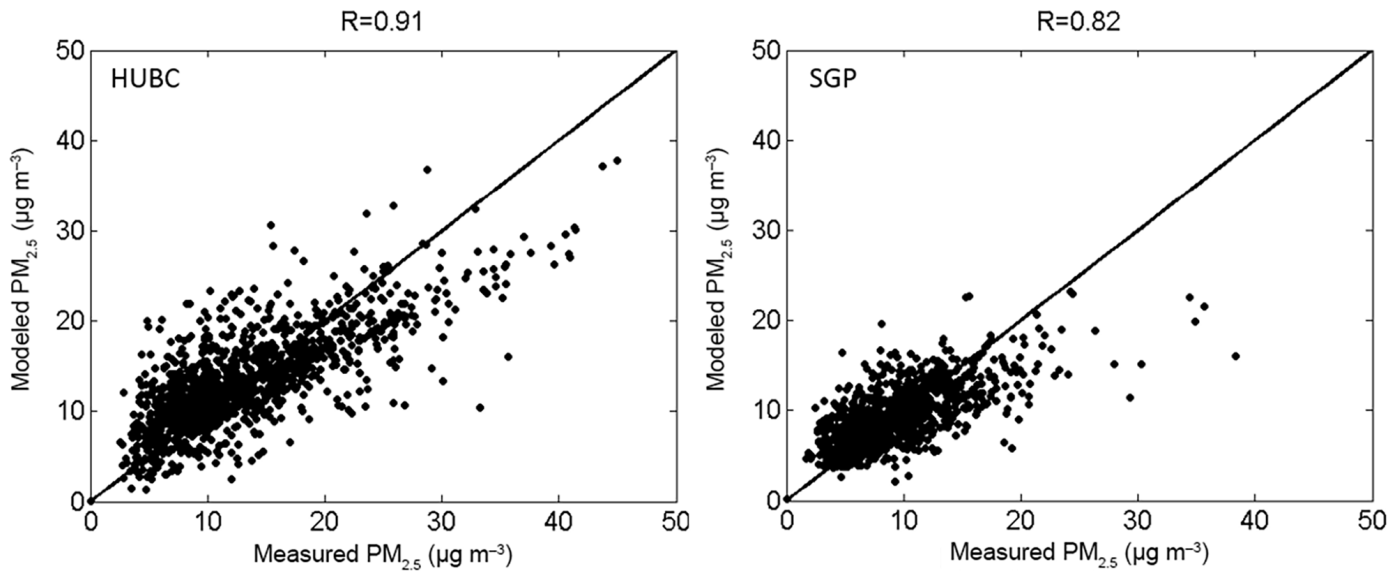

Figure 12. Comparison of daily average PM2.5 between in situ measurements and model simulation at the HUBC site and ARM SGP site.

The Vaisala CL31 has the same laser system, wavelength and measurement range as CT25k but improved spatial and temporal resolution and algorithms for cloud amount and mixing layer height detection (Münkel et al., 2007). To estimate the possible response changing of the CL31 ceilometer in different years, we compared the same 3 years $(2012,2013$, 2014) of yearly average ceilometer backscatter profiles under nighttime clear conditions as used for the CT25K. The largest difference of the yearly average backscatter under nighttime clear conditions among the 3 years (2012, 2013 and 2014) is found within $3 \%$ for the backscatter below $150 \mathrm{~m}$. The principle of the algorithm (Eqs. 1 to 10) is applicable to most lidars with small overlap distance. So it is possible to use the model with the Vaisala CL31. In the test, we used 4 years (from 2012 to 2015) of measurements of Vaisala CL31 ceilometer backscatter and the surface meteorological conditions provided by the ARM SGP site and the FRM/FEM PM2.5 mass concentration from the nearest EPA site $\left(36.697^{\circ} \mathrm{N}\right.$ and $97.081^{\circ} \mathrm{W}$; Air Quality System Data Mart, available via http://www.epa.gov/airdata). The same cross-validation procedure was implemented in the measurements at the ARM SGP site under daytime clear, daytime cloudy and nighttime periods. For the hourly average PM2.5, the cross-validation results (Fig. 11) show that the performance of the model with meteorological variables (Eq. 10) at the ARM SGP site was not as good as that of the HUBC site, but the model without meteorological variables (Eq. 9) performed better at the ARM SGP site than at the HUBC site during daytime cloudy and nighttime periods. That could be due to the different aerosol type and composition which are associated with the hygroscopic growth of aerosols at the SGP area and the DC area. When the model (Eq. 12) is applied on the daily average PM2.5, the average $\mathrm{CVR}^{2}$ out of the 100 independent cross-validations is 0.82 and 0.66 at the HUBC site and ARM SGP site, respectively. That means the model (Eq. 12) can explain $\sim 82$ and $\sim 66 \%$ of the variability in daily average PM2.5 at the HUBC site and ARM SGP site, respectively. The correlation coefficient between the in situ measurements of PM2.5 and the simulation based on the fitted parameters of the fitting with the median $\mathrm{CVR}^{2}$ out of the 100 independent cross-validations is 0.91 and 0.82 , respectively (Fig. 12). 


\section{Discussion}

Remote sensing of PM2.5 is generally based on AOD measurements due to its strong relationship with PM2.5. For nearly all the passive instruments, the measurements of AOD rely on solar radiation. Ceilometers are compact, low-cost and unattended operational lidars and have been broadly used around the world. Although their laser power is relatively lower, the advantages of the small overlap distance and unattended and continuous operation make ceilometers suitable for remote sensing of aerosols near the surface. Moreover, the measurements of ceilometers do not rely on solar radiation, which makes them capable of retrieving aerosols during cloudy or nighttime periods.

In this study, an empirical model based on the regression between PM2.5 concentrations and ceilometer backscatter measurements was developed and tested with 6 years of observations at the HUBC site. The empirical model can explain $\sim 56, \sim 34$ and $\sim 42 \%$ of the variability in the hourly average PM2.5, respectively, during the daytime clear, daytime cloudy and nighttime periods. During the daytime clear periods the prediction capability was close to that of the model combining AOD and backscatter (explain $\sim 60 \%$ of the variability) developed by $\mathrm{Li}$ et al. (2016), while during the daytime cloudy or nighttime period only the empirical model, which is independent of AOD, is available for the PM2.5 retrieval.

The impacts of meteorological conditions on the relationship between the in situ measured PM2.5 and the ceilometermeasured backscatter were analyzed. The prominent positive relationship found between the surface temperature and the PM2.5/ backscatter ratio could be due to the faster $\mathrm{SO}_{2}$ oxidation under higher temperature given that the dominant aerosol chemical composition is sulfate in the eastern United States. The measured relative humidity showed a significant negative association with the PM2.5/backscatter ratio, which could be due to hygroscopic growth of aerosols. The wind speed also showed a negative association with the PM2.5/backscatter ratio, but the relationship between the measured wind direction and PM2.5/backscatter ratio was found to not be obvious at the HUBC site. However, it is noteworthy that wind direction can be related to aerosol transportation and is usually associated with aerosol concentration and type. Although there was no significant association of the wind direction with the PM2.5 / backscatter ratio at the HUBC site, wind direction impacts could be significant at other places where transported aerosols like dust are found near the surface. Aerosol properties usually vary seasonally due to the seasonally varied meteorological conditions, large-scale transportation and local emission of anthropogenic and natural aerosols. Taking into account the meteorological conditions in the model can to some extent mitigate the seasonal impacts on the PM2.5 retrieval, and conducting the seasonal fitting can further improve the model predicting capability. Overall, the model with the seasonally fitted pa- rameters can explain $\sim 48 \%$ of the variability in the hourly PM2.5 including during daytime clear, daytime cloudy and nighttime periods at the HUBC site. Aerosol physical and chemical characteristics which are associated with aerosol dry mass and optical properties could vary at different locations. So a test was implemented based on the observations from the ARM SGP site, which is geographically and climatologically different from the HUBC site. The results show that the impacts of meteorological conditions on the retrieval of PM2.5 using the ceilometer backscatter at the ARM SGP site are not as prominent as those at the HUBC site. That could be due to the different aerosol types in the SGP area and the DC area. In addition, the model parameters could be different for different aerosol types or in different climatic regions. That is because the relationship between PM2.5 and aerosol backscatter is related to aerosol types and sizes ( $\mathrm{Li}$ et al., 2016), and the relationship between meteorological conditions and aerosols (i.e. size, composition) could vary with variation of aerosol types or climatic regions. Overall, the regression model using the ceilometer backscatter with meteorological variables could explain around 66 and $82 \%$ of the variability in the daily average PM2.5 at the ARM SGP site and the HUBC site, respectively. It is worth noting that both the instrument hardware-related background signals and software-related artifacts could impact attenuated backscatter profiles observed by ceilometers. Further processing of attenuated backscatter profiles is needed to get accurate attenuated backscatter observations from ceilometers especially under low signal-to-noise ratio situations (Kotthaus et al., 2016). In this study, we only use the attenuated backscatter at low altitude, where both the Vaisala CT25k and CL31 have high signal-to-noise ratio for lidar return signals and hourly average will also decrease noise. So the potential background signals and systematic artifacts should have small impacts on the regression model performance. However, the parameters of the regression model could be different for different instruments.

The most important objectives of this study were to develop an algorithm for remote sensing PM2.5 during cloudy and nighttime periods by using ceilometer-measured backscatter. Retrievals of PM2.5 during cloudy or nighttime periods are very rare based on current remote-sensing methods. A large number of ceilometers have been used over the world, especially in the Europe and United States. The exploitation of the ceilometer on PM2.5 remote sensing could provide important information for air quality purpose, especially in helping to improve PM2.5 forecast over a larger area and can help fill the gaps among the EPA stations. Moreover that will largely increase the monitoring of air quality during cloudy or/and nighttime periods.

Data availability. EPA data: https://aqs.epa.gov/api. ARM SGP site: http://www.archive.arm.gov/discovery. Contact Siwei Li: siwei.li@howard.edu. 
Competing interests. The authors declare that they have no conflict of interest.

Acknowledgements. This work was supported by the National Oceanic and Atmospheric Administration, Educational Partnership Program, US Department of Commerce, under agreement no. NA11SEC4810003, and supported by the National Aeronautics and Space Administration grant nos. NNX08BA42A and NNX10AQ11A.

Edited by: P. Stammes

Reviewed by: W. Thomas and R. Koelemeijer

\section{References}

Bell, M. L., Ebisu, K., and Belanger, K.: Ambient air pollution and low birth weight in Connecticut and Massachusetts, Environ. Health Persp., 115, 1118-1124, 2007.

Chu, D. A., Ferrare, R., Szykman, J., Lewis, J., Scarino, A., Hains, J., Burton, S., Chen, G., Tsai, T., Hostetler, C., Hair, J., Holben, B., and Crawford, J.: Regional characteristics of the relationship between columnar AOD and surface PM2.5: Application of lidar aerosol extinction profiles over BaltimoreeWashington Corridor during DISCOVER-AQ, Atmos. Environ., 101, 338-349, 2015.

Chudnovsky, A., Lyapustin, A., Wang, Y., Tang, C., Schwartz, J., and Koutrakis, P.: High resolution aerosol data from MODIS satellite for urban air quality studies, Cent. Eur. J. Geosci., 6, 17-26, https://doi.org/10.2478/s13533-012-0145-4, 2014.

Di Nicolantonio, W., Cacciari, A., and Tomasi, C.: Particulate matter at surface, Northern Italy monitoring based on satellite remote sensing, meteorological fields, and in-situ samplings, IEEE J. Selected Topics Appl. Earth Observ. Remote. Sens., 2, 284-292, 2009.

Dominici, F., Peng, R. D., Bell, M. L., Pham, L., McDermott, A., Zeger, S. L., and Samet, J. M.: Fine particulate air pollution and hospital admission for cardiovascular and respiratory diseases, JAMA, 295, 1127-1134, 2006.

Engel-Cox, J. A., Holloman, C. H., Coutant, B. W., and Hoff, R. M.: Qualitative and quantitative evaluation of MODIS satellite sensor data for regional and urban scale air quality, Atmos. Environ., 38, 2495-2509, 2004.

Franklin, M., Zeka, A., and Schwartz, J.: Association between PM2.5 and all-cause and specific-cause mortality in 27 US communities, J. Expo. Sci. Environ. Epidemiol., 17, 279-287, 2007.

Gent, J. F., Triche, E. W., Holford, T. R., Belanger, K., Bracken, M. B., Beckett, W. S., and Leaderer, B. P.: Association of low-level ozone and fine particles with respiratory symptoms in children with asthma, JAMA, 290, 1859-1867, 2003.

Gent, J. F., Koutrakis, P., Belanger, K., Triche, E., Holford, T. R., Bracken, M. B., and Leaderer, B. P.: Symptoms and medication use in children with asthma and traffic-related sources of fine particle pollution, Environ. Health Persp., 117, 1168-1174, 2009.

Gupta, P. and Christopher, S. A.: Seven year particulate matter air quality assessment from surface and satellite measurements, Atmos. Chem. Phys., 8, 3311-3324, https://doi.org/10.5194/acp-83311-2008, 2008.
Gupta, P., Christopher, S. A., Wang, J., Gehrig, R., Lee, Y., and Kumar, N.: Satellite remote sensing of particulate matter and air quality assessment over global cities, Atmos. Environ., 40, 58805892, 2006.

Hand, J. L., Schichtel, B. A., Malm, W. C., and Pitchford, M. L.: Particulate sulfate ion concentration and $\mathrm{SO}_{2}$ emission trends in the United States from the early 1990s through 2010, Atmos. Chem. Phys., 12, 10353-10365, https://doi.org/10.5194/acp-1210353-2012, 2012.

Harrison, L. and Michalsky, J.: Objective algorithms for the retrieval of optical depths from ground-based measurements, Appl. Opt., 33, 335126-335132, 1994.

Harrison, L., Michalsky, J., and Berndt, J.: Automated multifilter rotating shadow-band radiometer: An instrument for optical depth and radiation measurements, Appl. Opt., 33, 5118-5125, 1994.

Heese, B., Flentje, H., Althausen, D., Ansmann, A., and Frey, S.: Ceilometer lidar comparison: backscatter coefficient retrieval and signal-to-noise ratio determination, Atmos. Meas. Tech., 3, 1763-1770, https://doi.org/10.5194/amt-3-1763-2010, 2010.

Hu, X., Lance, W., Al-Hamdan, M., Crosson, W., Estes Jr, M., Estes, S., Quattrochi, D., Sarnat, J., and Liu, Y.: Estimating Groundlevel PM2.5 concentrations in the Southeastern U.S. using Geographically Weighted Regression, Environ. Res., 121, 1-10, 2013.

Hu, X., Lance, W., Lyapustin, A., Wang, Y., Al-Hamdan, M., Crosson, W., Estes Jr, M., Estes, S., Quattrochi, D., Puttaswamy, S., and Liu, Y.: Estimating Ground-level PM2.5 Concentrations in the Southeastern U.S. using MAIAC AOD Retrievals and a Two-Stage Model, Remote Sens. Environ., 140, 220-232, 2014.

Kessner, A., Wang, J., Levy, R., and Colarco, P.: Remote sensing of surface visibility from space: a look at the United States East Coast, Atmos. Environ., 81, 136e147, https://doi.org/10.1016/j.atmosenv.2013.08.050, 2013.

Koelemeijer, R. B. A., Homan, C. D., and Matthijsen, J.: Comparison of spatial and temporal variations of aerosol optical thickness and particulate matter over Europe, Atmos. Environ., 40, 5304 5315, 2006.

Kotthaus, S., O’Connor, E., Münkel, C., Charlton-Perez, C., Haeffelin, M., Gabey, A. M., and Grimmond, C. S. B.: Recommendations for processing atmospheric attenuated backscatter profiles from Vaisala CL31 ceilometers, Atmos. Meas. Tech., 9, 37693791, https://doi.org/10.5194/amt-9-3769-2016, 2016.

Krewski, D., Jerrett, M., Burnett, R. T., Ma, R., Hughes, E., Shi, Y., Turner, M. C., Pope, C. A., Thurston, G., Calle, E. E., and Thun, M. J.: Extended follow-up and spatial analysis of the American Cancer Society study linking particulate air pollution and mortality, Health Effects Inst. Research., 2009.

Lee, H. J., Coull, B. A., Bell, M. L., and Koutrakis, P.: Use of satellite-based aerosol optical depth and spatial clustering to predict ambient PM2.5 concentrations, Environ Res., 118, 8-15, https://doi.org/10.1016/j.envres.2012.06.011, 2012.

Lepeule, J., Laden, F., Dockery, D., and Schwartz, J.: Chronic exposure to fine particles and mortality: an extended follow up of the Harvard six cities study from 1974 to 2009, Environ. Health Persp., 120, 965-970, https://doi.org/10.1289/ehp.1104660, 2012.

Li, S., Joseph, E., and Min, Q.: Remote sensing of ground-level PM2.5 combining AOD and backscat- 
tering profile, Remote Sens. Environ., 183, 120-128, https://doi.org/10.1016/j.rse.2016.05.025, 2016.

Liu, Y., Park, R. J., Jacob, D. J., Li, Q. B., Kilaru, V., and Sarnat, J. A.: Mapping annual mean ground-level PM2.5 concentrations using Multiangle Imaging Spectroradiometer aerosol optical thickness over the contiguous United States, J. Geophys. Res., 109, D22206, https://doi.org/10.1029/2004JD005025, 2004.

Liu, Y., Sarnat, J. A., Kilaru, V., Jacob, D. J., and Koutrakis, P.: Estimating Ground-Level PM2.5 in the Eastern United States Using Satellite Remote Sensing, Environ. Sci. Technol., 39, 32693278, https://doi.org/10.1021/es049352m, 2005.

Liu, Y., Paciorek, C. J., and Koutrakis, P.: Estimating Regional Spatial and Temporal Variability of PM Concentrations Using Satellite Data, Meteorology, and Land Use Information, Environ. Health Persp., 117, 886-892, 2009.

Ma, Z., Hu, X., Huang, L., Bi, J., and Liu, Y.: Estimating Ground-Level PM2.5 in China Using Satellite Remote Sensing, Environ. Sci. Technol., 48, 7436-7444, https://doi.org/10.1021/es5009399, 2014.

Markowicz, K. M., Flatau, P. J., Kardas, A. E., Remiszewska, J., Stelmaszczyk, K., and Woeste, L.: Ceilometer Retrieval of the Boundary Layer Vertical Aerosol Extinction Structure, J. Atmos. Ocean. Technol., 25, 928-944, https://doi.org/10.1175/2007JTECHA1016.1, 2008.

Miller, K., Siscovick, D., Sheppard, L., Shepherd, K., Sullivan, J., Anderson, G., and Kaufman, J.: Long-term exposure to air pollution and incidence of cardiovascular events in women, New England Journal of Medicine, 356, 447-458, 2007.

Min, Q. and Harrison, L.: Cloud properties derived from surface MFRSR measurements and comparison with GOES results at the ARM SGP site, Geophys. Res. Lett., 23, 1641-1644, 1996.

Münkel, C., Eresmaa, N., Räsänen, J., and Karppinen, A.: Retrieval of mixing height and dust concentration with lidar ceilometer, Bound.-Lay. Meteorol., 124, 117-128, https://doi.org/10.1007/s10546-006-9103-3, 2007.

Paciorek, C. J., Liu, Y., Moreno-Macias, H., and Kondragunta, S.: Spatiotemporal Associations between GOES Aerosol Optical Depth Retrievals and Ground-Level PM2.5, Environ. Sci. Technol., 42, 5800-5806, https://doi.org/10.1021/es703181j, 2008.

Pope, C. A., Burnett, R. T., Thun, M. J., Calle, E. E., Krewski, D., Ito, K., and Thurston, G. D.: Lung cancer, cardiopulmonary mortality, and long-term exposure to fine particulate pollution. JAMA: the Journal of the American Medical Association, 287, 1132-1141, 2002.

Pope, C. A., Ezzati, M., and Dockery, D. W.: Fine-particulate air pollution and life expectancy in the United States, N England J Med., 360, 376-386, https://doi.org/10.1056/NEJMsa0805646, 2009.

Samet, J. M., Dominici, F., Curriero, F. C., Coursac, I., and Zeger, S. L.: Fine particulate air pollution and mortality in 20 U.S. cities, 1987-1994, N. Engl. J. Med., 343, 1742-1749, https://doi.org/10.1056/NEJM200012143432401, 2000.

Schaap, M., Apituley, A., Timmermans, R. M. A., Koelemeijer, R. B. A., and de Leeuw, G.: Exploring the relation between aerosol optical depth and $\mathrm{PM}_{2.5}$ at Cabauw, the Netherlands, Atmos. Chem. Phys., 9, 909-925, https://doi.org/10.5194/acp-9909-2009, 2009.
Schwartz, J., Dockery, D. W., and Neas, L. M.: Is daily mortality associated specifically with fine particles?, J. Air Waste Manag. Assoc., 46, 927-939, 1996.

Slama, R., Morgenstern, V., Cyrys, J., Zutavern, A., Herbarth, O., Wichmann, H. E., and Heinrich, J.: Traffic-related atmospheric pollutants levels during pregnancy and offspring's term birth weight, A study relying on a land-use regression exposure model, Environ. Health Persp., 115, 1283-1292, 2007.

Sorek-Hamer, M., Strawa, W. A., Chatfield, B. R., Esswein, R., Cohen, A., and Broday, M. D.: Improved retrieval of PM2.5 from satellite data products using non-linear methods, Environ. Pollut., 182, 417-423, https://doi.org/10.1016/j.envpol.2013.08.002, 2013.

Strawa, A. W., Chatfield, R. B., Legg, M., Scarnato, B., and Esswein, R.: Improving Retrievals of Regional PM2.5 Concentrations From MODIS and OMI MultiSatellite Observations, J. Air Waste Manage. Assoc., 63, https://doi.org/10.1080/10962247.2013.822838, 2013.

Tai, P. K. A., Mickley, L. J., and Jacob, D. J.: Correlations between fine particulate matter (PM2.5) and meteorological variables in the United States: Implications for the sensitivity of PM2.5 to climate change, Atmos. Environ., 44, 3976-3984, https://doi.org/10.1016/j.atmosenv.2010.06.060, 2010.

Tsaknakis, G., Papayannis, A., Kokkalis, P., Amiridis, V., Kambezidis, H. D., Mamouri, R. E., Georgoussis, G., and Avdikos, G.: Inter-comparison of lidar and ceilometer retrievals for aerosol and Planetary Boundary Layer profiling over Athens, Greece, Atmos. Meas. Tech., 4, 1261-1273, https://doi.org/10.5194/amt-41261-2011, 2011.

van Donkelaar, A., Martin, R. V., and Park, R. J.: Estimating ground-level PM2.5 using aerosol optical depth determined from satellite remote sensing, J. Geophys. Res., 111, D21201, https://doi.org/10.1029/2005JD006996, 2006.

van Donkelaar, A., Martin, R. V., Brauer, M., Kahn, R., Levy, R., Verduzco, C., and Villeneuve, P. J.: Global estimates of ambient fine particulate matter concentrations from satellite-based aerosol optical depth: Development and application, Environ. Health Persp., 118, 847-855, 2010.

Wiegner, M. and Geiß, A.L Aerosol profiling with the Jenoptik ceilometer CHM15kx, Atmos. Meas. Tech., 5, 1953-1964, https://doi.org/10.5194/amt-5-1953-2012, 2012.

Wiegner, M. and Gasteiger, J.: Correction of water vapor absorption for aerosol remote sensing with ceilometers, Atmos. Meas. Tech., 8, 3971-3984, https://doi.org/10.5194/amt-8-3971-2015, 2015.

Wiegner, M., Madonna, F., Binietoglou, I., Forkel, R., Gasteiger, J., Geiß, A., Pappalardo, G., Schäfer, K., and Thomas, W.: What is the benefit of ceilometers for aerosol remote sensing? An answer from EARLINET, Atmos. Meas. Tech., 7, 1979-1997, https://doi.org/10.5194/amt-7-1979-2014, 2014.

Wiscombe, W.: Improved mie scattering algorithms, Appl. Opt., 19, 1505-1509, 1980.

Xu, J.-W., Martin, R. V., van Donkelaar, A., Kim, J., Choi, M., Zhang, Q., Geng, G., Liu, Y., Ma, Z., Huang, L., Wang, Y., Chen, H., Che, H., Lin, P., and Lin, N.: Estimating ground-level $\mathrm{PM}_{2.5}$ in eastern China using aerosol optical depth determined from the GOCI satellite instrument, Atmos. Chem. Phys., 15, 1313313144, https://doi.org/10.5194/acp-15-13133-2015, 2015. 